\title{
Development of a superstructure optimization framework for the design of municipal solid waste facilities
}

\author{
Channarong Puchongkawarin * (D) and Supatpong Mattaraj
}

\begin{abstract}
The main objective of this study is to develop a decision-making tool for the design of the optimal municipal solid waste (MSW) facilities based on superstructure optimization. Currently, the disposal of MSW is a major problem due to the lack of awareness of the negative impacts resulting from dumping MSW into the environment. This poses a challenge for the authorities. MSW valorization such as anaerobic digestion, pyrolysis, and gasification has been increasingly focused on as an approach when handling MSW to enhance both economic and environmental sustainability. However, with an increasing array of processing technologies, the design of MSW facilities involving the integration of these technologies is becoming tedious and unmanageable. To deal with this problem, superstructure optimization is proposed. It is an effective tool for the design of several chemical processes because it is able to consider all potential process alternatives including the optimal solution using mathematical models based on mass and energy balances. Uncertainty is incorporated into the optimization framework to enhance the robustness of the solution. The proposed methodology was applied in the design process of the MSW facility in Ubon Rathathani Province, Thailand, with the objective function of maximizing the profit. The optimization problem was developed as Mixed Integer Linear Programming and it was solved using an optimization platform, General Algebraic Modeling System, with CPLEX as the solver related to obtaining the optimal solution. The results show there to be as positive profit that is economically viable compared to the use of landfill technology.
\end{abstract}

Keywords: Superstructure optimization, MSW management, Waste valorization, Process design

\section{Introduction}

Municipal solid waste (MSW) is an undesirable material that is thrown away by households, e.g. packaging, plastic, and food waste, etc. [1]. It is typically collected and disposed of by the municipal authorities. MSW has increasingly become an issue of global concern as the amount of MSW increases. It is reported that the amount of MSW generated worldwide is around 1300 Mt and the generation of MSW is expected to reach $2200 \mathrm{Mt}$ by 2025 [2] as a result of a growing population, urbanization, and changes in life style [3]. Specifically, the MSW generated in Thailand totaled approximate

\footnotetext{
* Correspondence: channarong.p@ubu.ac.th

Department of Chemical Engineering, Ubon Ratchathani University, Ubon Ratchathani 34190, Thailand
}

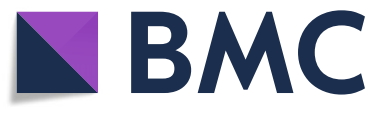

(- The Author(s). 2020 Open Access This article is licensed under a Creative Commons Attribution 4.0 International License, which permits use, sharing, adaptation, distribution and reproduction in any medium or format, as long as you give

appropriate credit to the original author(s) and the source, provide a link to the Creative Commons licence, and indicate if changes were made. The images or other third party material in this article are included in the article's Creative Commons licence, unless indicated otherwise in a credit line to the material. If material is not included in the article's Creative Commons licence and your intended use is not permitted by statutory regulation or exceeds the permitted use, you will need to obtain permission directly from the copyright holder. To view a copy of this licence, visit http://creativecommons.org/licenses/by/4.0/. found that $39 \%$ of the total MSW is disposed of appropriately, $34 \%$ is reused/recycled, and the remainder is still disposed of incorrectly [5]. Regarding waste reuse/ recycling, waste can be recycled into valuable products, e.g. glass, paper, and plastic. An increase in MSW can cause serious problems for the environment and human health such as groundwater contamination and air pollution. MSW management is a challenging task due to the limited resources and increasing population. Inefficient waste management may cause significant environmental problems, e.g., the generation of greenhouse gases and an increase in the number of bacteria causing disease in humans. The common approach to disposing of MSW in developing countries includes open dumping, sanitary 
landfills, and incineration. These are commonly used technologies despite the high potential to pollute the environment because of the relatively low investment cost [2]. The main problem of the conventional disposal approach is the shortage of landfill and dumping sites inland [6]. This requires a sustainable and efficient approach to be present in the waste management system. However, this is a challenging task due to the limited resources and increasing population.

Recently, several studies in the field of waste management have focused on resource recovery and minimizing waste disposal. Various technologies and initiatives have been developed as alternatives for waste disposal by considering MSW a valuable resource [7, 8]. These technologies can generate electricity, useful heat, syngas, biodiesel, compost, fertilizer, and other by-products [9] so the concept of integrated waste management can be an effective and sustainable waste management method [10]. The design of integrated waste processing technologies has been performed using many concepts and tools including zero waste [11], urban metabolism [12], substance flow analysis [13] and life cycle assessments $[14,15]$. However, these techniques do not guarantee an optimal solution. With an increasing array of treatment technologies for waste management, the selection of the most appropriate treatment technology is becoming a challenging task since it involves several parties and different factors within complex decision-making. Each processing pathway has its own pros and cons including investment, operating, and resource recovery. This calls for a systematic technique or holistic approach to select the optimal solution and the most suitable technology. Superstructure optimization is one of the most powerful approaches used to handle such problems. It has proven to be an effective approach for the design of chemical engineering processes [16]. It was introduced in Umeda et al. [17] and involved three main steps: i) postulating a superstructure which proposes a set of all feasible process structures, ii) translating the superstructure into a mathematical model, and iii) computing the optimal process structure based on the proposed mathematical model using the chosen numerical algorithms [16]. The superstructure initially assumes all possible alternatives related to the potential conversion technologies, including any optimal solutions that are hidden. A common way to formulate a superstructure involves a mathematical model of mass and energy balances. This framework has been applied previously with several applications, e.g., water network [18] and wastewater treatment [19]. There have been a few studies investigating the application of superstructure optimization in MSW management [20-24]. Although previous studies have presented the potential of superstructure optimization in order to handle the simultaneous selection of waste processing technologies and operating conditions, they have not dealt with evaluation of solid/liquid residue such as the residual materials as well as wastewater from waste processing technologies and uncertainty analysis. This consequently does not account for the concept of integrating waste processing technologies. In this study, the main objective of this study is to develop a decisionmaking tool based on the concept of superstructure optimization for the design of MSW management to convert waste into multiple products through the integration of various processing technologies. The application of the proposed framework is illustrated by a case study in Ubon Ratchathani Province, Thailand. The novelty of this study is to incorporate the material recovery and solid/liquid residue explicitly from waste processing technologies into the superstructure optimization framework to improve economic viability of the waste management system. Also, the uncertainty analysis is incorporated into the unified framework to enhance robustness of the optimal solution. Note that it is assumed that MSW is separated at the point of generation or source separation because it has been proven that the source separation can reduce the amount of residual waste, improve the recovery of recyclable materials, which can potentially reduce the negative outcomes and provide financial as well as environmental benefits. The source separation typically involves higher collection costs, new collecting vehicles, additional workers required, and new equipment [25]. However, we focus mainly on the selection of the optimal waste processing technology in this study so the cost and energy associated with the source separation and transportation are not included in the superstructure. The paper is organized as follows: the first section reviews the previous studies on the design of waste management, followed by the proposed methodology regarding superstructures and the case study using the proposed approach and the results. Finally, the key contributions will be concluded in the last section.

\section{Design of MSW facilities}

MSW management involves a set of activities used to manage MSW from its origin through final disposal [26]. This includes transportation, collection, treatment approaches, and final disposal in order to deal with all of the materials in the waste stream to protect human health, promote environmental quality, support economic productivity, and enhance sustainability. This is a challenging task as it requires the fulfilment of technical, economic, environmental, and social constraints. Various computer-aided methods have been developed to help decision-makers to reach a conclusion [27]. Several studies have investigated solid waste management focusing on economic, energy and environmental analysis for 
specific treatment and processing technologies in specific areas. Khan et al. [28] developed a technoeconomic model for the economic assessment of MSW utilization pathways. The developed model was able to determine suitable locations for the waste conversion facilities based on a geographic information system. It compared nine different waste management scenarios which included landfill, composting, and gasification. The proposed method was applied to a case study in $\mathrm{Al}-$ berta, Canada. Some of the studies also used the life cycle assessment as a tool to examine the environmental impact of the selected process alternatives $[15,29]$. However, these techniques do not guarantee that the selected processing technology is optimal in terms of the economic, energy, and environmental aspects. To address the problem, a wide variety of techniques and optimization models have been developed in the field of process system engineering for the design of waste management systems. Recently, process design and optimization for MSW management has received attention. $\mathrm{Ng}$ et al. [22] developed an optimization model to use in the supply chain design of MSW management. The proposed method allowed for the optimal selection of the thermochemical and biochemical treatment technologies. However, the developed optimization framework did not consider the potential of recyclable materials which can be further processed to compensate for any expenses. Santibanez-Aguilar et al. [30] developed a mathematical programming model used to determine the reuse of MSW to maximize the economic objective while considering the environmental and safety aspects simultaneously. Satchatippavarn et al. [24] employed a superstructure optimization approach together with the biorefinery concept for the design of an integrated MSW management system. A case study in Bangkok presented the potentials and benefits related to achieving self-sufficiency. Niziolek et al. [31] proposed a superstructure-based approach to produce liquid transportation fuels, olefins, and aromatics from MSW. The non-convex Mixed Integer Nonlinear Programming (MINLP) optimization model was formulated and solved by using deterministic global optimization solvers to optimality. Rizwan et al. [23] developed an optimization framework to optimize the processing route to convert MSW into energy and valuable products. The optimization model was formulated as MINLP which was later linearized into Mixed Integer Linear Programming (MILP). The proposed method was applied to a case study in Abu Dhabi. The optimal results consisted of an integrated MSW conversion pathway. Morero et al. [32] presented an optimization model for the selection of an MSW treatment focusing on anaerobic digestion (AD). It was able to quantify the advantages of $\mathrm{AD}$ over landfilling and composting. Although there have been a number of studies focusing on the design of MSW management based on superstructure optimization, the potential of resource recovery from waste management is not focused on. The residue stream including biosolids as well as leachates and the uncertainty analysis are not accounted for. This can change the optimal processing technology. In this study, the research gap is addressed by developing a systematic framework based on superstructure optimization for the design of a sustainable waste processing pathway. This can produce valuable products such as electricity, bioethanol, and recycled materials under the presence of uncertainty.

\section{Framework for the design of waste management using superstructure optimization}

The design of a sustainable waste management facility involves multiple waste streams from particular locations to determine the best integrated waste processing technology to convert the waste into valuable resources under a particular set of constraints. This calls for a rigorous and efficient approach in order to account for all possible process alternatives. The objective of this study is to develop a model-based methodology using superstructure optimization to determine the optimal MSW processing facility that can achieve economic sustainability. It is expected that all wastes can be utilized and converted into energy and valuable products under economic consideration. In this study, the framework of the superstructure optimization in the design of the waste processing pathway is presented in Fig. 1. It consists of 4 steps and each step in the framework can be explained as follows:

\section{Identification of waste and process technologies}

In the first step, the identification of the MSW and the possible waste processing technologies to include in the superstructure is carried out. This involves defining the quantity and composition of the waste in a given location. Then the possible waste processing technologies are investigated for each waste stream. The preliminary selection of the waste processing technologies is screened based on information regarding technoeconomics (cost of each technology and recovery efficiency) and process efficiency. This can be reviewed using technical reports, the published literature, and mathematical models.

\section{Development of a superstructure}

After defining the amount of waste, the waste composition and the possible waste processing technologies in use, it is possible to combine the information from the first step into the superstructure as illustrated in Fig. 2. The superstructure consists of different compositions of 


\section{Identification of waste and}
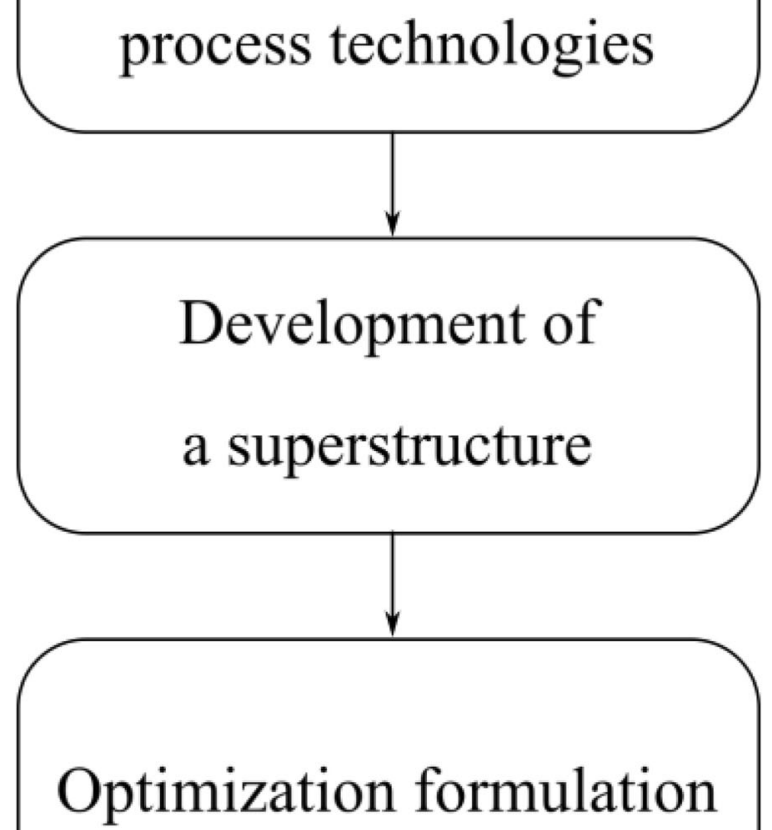

\section{Uncertainty analysis}

of an optimal MSW

waste, possible waste process technologies, potential products, and likely residues. It is divided into three stages: waste segregation (index $i$ ), waste processing (index $p$ ) and products (index $k$ ). The incoming MSW is segregated into different fractions of waste. Then the waste is sent to the waste processing technology to produce one or more products i.e. organic waste is sent to AD which can potentially produce electricity and fertilizer. The residue from the waste processing technology is also taken into account. For example, the residue from the material recovery facility (MRF) can be sent to incineration or landfill.

\section{Optimization formulation}

The superstructure optimization is formulated based on the material balance to optimize the MSW processing pathway in terms of economic sustainability. The optimization formulation involves two types of variables:

- Binary variable: $y$ - This type of variable is used to represent the selection of the waste processing technologies and the associated interconnections. It is equal to 1 if the corresponding technology is chosen; Otherwise, it is equal to 0.

- Continuous variable: $x$ - This variable represents the flow and concentration of the waste.

This study aims to evaluate and choose the best waste processing technology for the MSW treatment process in the early stages of design. Binary variables are important in this context because they can be used to select the most appropriate process technologies from among a set of process alternatives used to identify the optimal waste processing pathway. The optimization problem can be formulated as follows:

$$
\begin{gathered}
\max _{x, y} \operatorname{KPI}(x, y) \\
\text { s.t.h }(x)=0 \\
g(x, y) \leq 0 \\
x \in X, y \in\{0,1\}
\end{gathered}
$$

where KPI $(x, y)$ is the set of objective functions in which the economic or environmental indicator or both can be used. It is a function of both types of variable. $h(x)$ is the equality constraints representing the material balance. $g(x, y)$ is the inequality constraints referring to the design specification and environmental regulations, e.g., the maximum limit of the discharge. Details of the superstructure optimization is presented as follows.

\section{Objective function}

The maximization of the annual profit is selected as the objective function of the optimization model describing the MSW management given by:

$$
z=\sum_{k \in K} S A L E_{k}-\sum_{p \in P} C A P_{p}+\sum_{p \in P} O P E_{p}
$$

where $z$ is the annual profit (objective function); $C A P_{P}$ and $O P E_{P}$ are the annual capital cost and operating cost of the waste processing technology $p . S A L E_{k}$ is the annual revenue from selling the products, listed as $k$. The annual capital cost or the initial investment cost includes land acquisition, any equipment, raw material, and indirect costs such as the planning cost, contractual support, and financial services. The annual operating cost includes maintenance and labor. In this study, it is assumed that the annual capital and operating costs are 


\section{MSW}

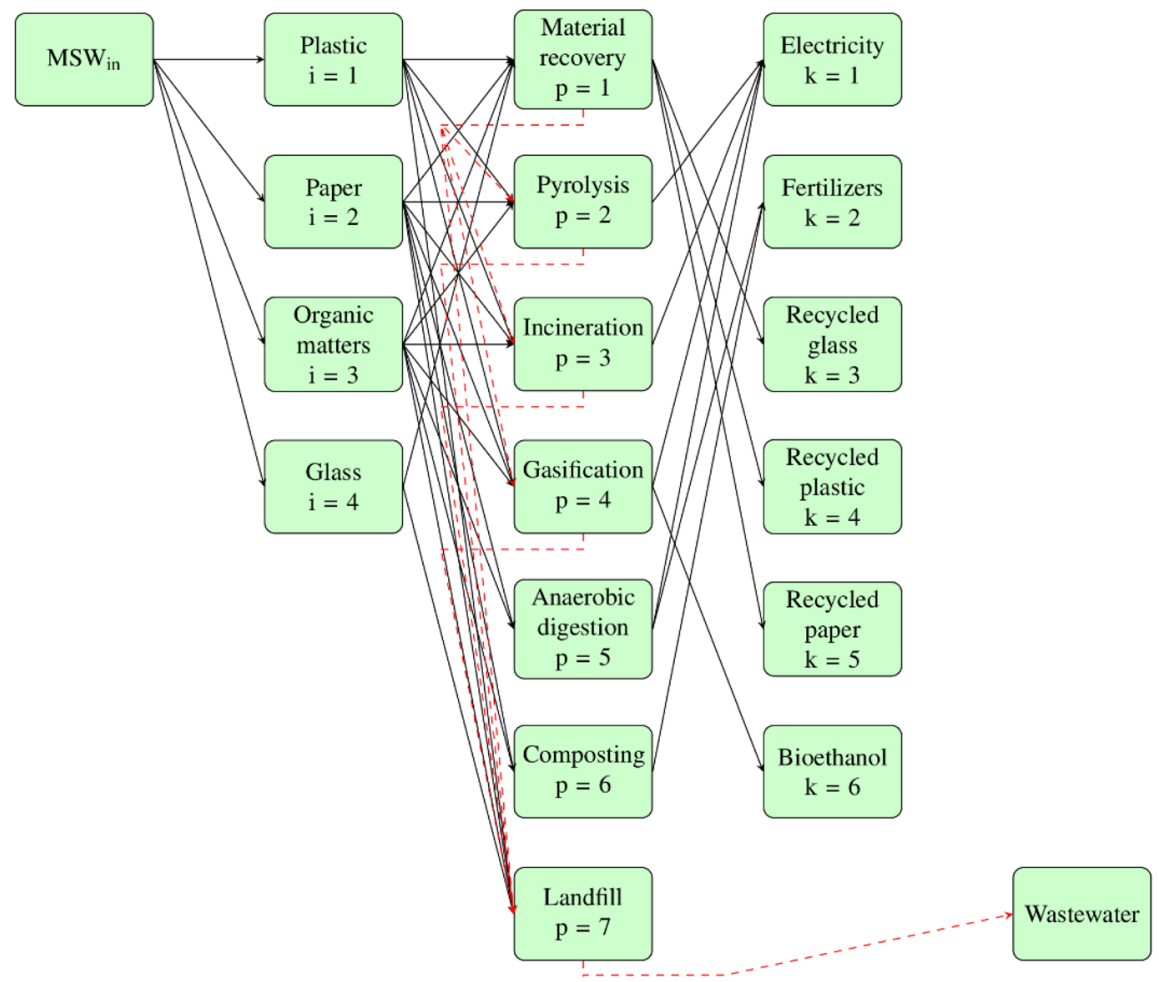

Fig. 2 Illustrative representation of the superstructure of the waste conversion

dependent linearly on the flow entering the processing technology. This can be calculated as follows:

$$
\begin{aligned}
& C A P_{P}=\sum_{i \in I} F_{i, p}^{i n} C C F_{p} \\
& O P E_{P}=\sum_{i \in I} F_{i, p}^{i n} C P F_{p}
\end{aligned}
$$

where $C C F_{p}$ and $C P F_{p}$ are the annual capital and operating cost factors of the waste processing technology $p$. $F_{i, p}^{i n}$ is the amount of waste $i$ sent to the waste processing technology $p$. The product sale $\left(S A L E_{k}\right)$ is determined as follows:

$$
S A L E_{k}=\sum_{p \in P} F_{p, k} P_{k}
$$

where $F_{p, k}$ is the amount of the product $k$ obtained from the waste processing technology $p$ and $P_{k}$ is the selling price of the products $k$.

\section{Material balance}

The superstructure optimization framework in this work is based on the material balance constraints. For each stage in the superstructure, the material balance needs to be satisfied. As the MSW contains several compositions, it initially needs to be segregated to make it easier for processing and utilization. In the first stage, the incoming MSW to this stage is segregated into different groups. For simplicity, the four most common fractions of MSW are used for this calculation including organic waste, glass, paper, and plastic. The overall mass balance in this stage is given by:

$$
M S W^{i n}=\sum_{i \in I} W_{i}
$$

where $M S W^{i n}$ is the flow of incoming MSW and $W_{i}$ is the amount of waste $i$. Different types of waste are sent to waste processing technologies as denoted by indices $p$.

$$
W_{i}=\sum_{p \in P} F_{i, p}
$$

where $F_{i, p}$ is the amount of waste $i$ sent to the processing technology $p$. Given the flow of the waste stream, the selection of each interconnection linked to different technologies for the MSW treatment facility is given by: 


$$
F^{l o} \cdot y \leq F \leq F^{u p} \cdot y
$$

where $F^{l o}$ and $F^{u p}$ is the lower and upper bounds of the flow of the waste streams. $y$ is the binary variable used to select the existence of the waste stream or waste processing technology. It is equal to 1 if the stream or technology is selected, otherwise it becomes 0 . In the second stage or the waste processing technology state, the flow of the waste streams entering the waste processing technology is described by:

$$
F_{p}^{i n}=\sum_{i \in I} F_{i, p}+\sum_{p^{\prime} \in P} F_{p^{\prime}, p}
$$

where $F_{p}^{i n}$ the flow of waste $i$ entering the waste processing technology $p . F_{p^{\prime}, p}$ is the flow of the waste from conversion technology $p^{\prime}$ to the waste processing technology $p$ (residual flow). Note that some waste processing technologies do not have residual streams, so the $F_{p}$ ,,$p$ is 0 . The amount of waste residue leaving the processing technology is calculated based on the efficiency of the waste processing technology as follows:

$$
\sum_{p^{\prime} \in P} F_{p^{\prime}, p}=F_{p}^{i n}\left(1-E_{p}\right)
$$

where $E_{p}$ is the efficiency of the processing technology $p$. The amount of product obtained from the waste processing technology is given by:

$$
\sum_{p \in P} F_{p, k}=\sum_{p \in P} F_{p}^{i n} Y I E L D_{p, k}
$$

where $Y I E L D_{p, k}$ is the yield of the product $k$ obtained from the waste processing technology $p$.

\section{Solution strategies}

The proposed superstructure optimization model in this study corresponds to MILP. This problem was modeled using the optimization platform, General Algebraic Modeling System. In this study, the CPLEX optimization solver is used for solving all of the problems to optimality.

\section{Uncertainty analysis}

Uncertainty analysis is performed to enhance the robustness of the solution. It is important to show that the waste processing facility is feasible to operate over the set of uncertain parameters. For example, the yield of products from each processing technology may change over time as well as be different from place to place. This may change the network of the waste processing technology so uncertainty has to therefore be considered during the design. In order to incorporate the uncertainties into the optimization problem, a common approach for handling uncertainties is two-stage stochastic programming. It is based on a probabilistic model considering uncertainty explicitly and there is the existence of recourse representing the corrective actions that are available after a set of uncertainties has been realized. Regarding the two-stage stochastic programming, a set of uncertainties is modeled using discrete or continuous probability distribution and incorporated into the optimization formulation. This leads to a robustsufficient solution or an expectedly optimal solution. Two-stage stochastic programming is commonly used in process design [33]. It involves a separation of the decision variables into two sets namely the first-stage decision and second-stage decision. In the first stage, the structural decisions are determined before the uncertainty is realized. The second stage involves operational decisions when the uncertain values are realized.

To account for a particular set of uncertainty in the optimization problem, it involves three steps: uncertainty characterization, uncertainty mapping and decisionmaking under uncertainty. In the first step, a set of uncertain parameters is identified and sampled using the Latin Hypercube Sampling technique. This is a statistical method used for scenario generation based on a predefined distribution function of uncertain parameters [34, 35]. In the second step, the optimization problem is solved separately for each scenario to investigate the impact of the uncertainty on the objective function. Finally, the optimization problem is reformulated using twostage stochastic programming (Eqs. (12) and (13)) and solved for different combinations of uncertain parameters obtained from the sampling. The robustness of the optimal result can be achieved using the following:

$$
\begin{aligned}
& \min _{\mathrm{x}, \mathrm{y}} E_{\theta}[K P I(x, y, \theta)] \\
& \text { s.t.h }(\mathrm{x}, \theta)=0 \\
& \mathrm{~g}(\mathrm{x}, \mathrm{y}, \theta) \leq 0 \\
& \quad \mathrm{x} \in \mathrm{X}, \mathrm{y} \in\{0,1\}, \theta \in\left\{\theta^{L O}, \theta^{U P}\right\}
\end{aligned}
$$

where $E_{\theta}[K P I(x, y, \theta)]$ is the expected value of the objective function in the presence of uncertainty and $\theta$ is the vector of uncertain parameters. The calculation of the expected value in the presence of uncertainty requires a large computational burden. The optimization problem in Eq. (12) can be reformulated into the deterministic equivalent as given by:

$$
\begin{gathered}
\min _{\mathrm{x}, \mathrm{y}} \sum_{s=1}^{S} P_{s} \cdot \operatorname{KPI}(x, y, s) \\
\text { s.t.h }(\mathrm{x}, \mathrm{s})=0 \\
\mathrm{~g}(\mathrm{x}, \mathrm{y}, \mathrm{s}) \leq 0 \\
\mathrm{x} \in \mathrm{X}, \mathrm{y} \in\{0,1\}, \mathrm{s} \in \mathrm{S}
\end{gathered}
$$

where $\mathrm{s}$ is the number of scenarios from the sampling and $P_{s}$ is the probability of the realization of uncertainty. 
Note that the number of equations increases with the number of scenarios.

\section{Case study}

The proposed approach has been applied to the design of a MSW treatment facility in Ubon Ratchathani Province in Thailand as a case study to identify economically sustainable MSW processing technologies. Ubon Ratchathani Province is a large city in the northeastern of Thailand with a population of 1.875 million. It daily generated $1.8 \mathrm{kt}$ of MSW in 2018 [4]. The MSW is currently collected by the local administrative organizations and delivered to solid waste disposal centers. Some areas that do not have a solid waste management system need to dispose their waste in their own areas. According to the report from the Pollution and Control Department [4], $34.4 \%$ of the total MSW in Ubon Ratchathani Province is separated at its sources and re-utilized as recyclable materials and fertilizers, $39.1 \%$ of the total MSW is disposed appropriately such as sending to landfills which can potentially cause pollution problems, and the remainder of MSW is disposed inappropriately such as open waste burning. This is becoming a disastrous issue because of the rapidly growing population. This calls for better waste management for the improvement of the current practice. In terms of waste characteristics, the MSW is categorized as organic waste (61\%), plastic $(17 \%)$, glass $(6 \%)$, papers $(8 \%)$, metal $(2 \%)$, wood $(1 \%)$, rubber/leather $(1 \%)$, cloth $(1 \%)$, and other waste $(3 \%)$ [36]. For the sake of simplicity, the four largest compositions of MSW are considered in this study. The developed approach is able to provide suggestions to determine promising technologies for waste management.

As mentioned previously, superstructure optimization is used for the design of an MSW processing pathway. The superstructure is illustrated in Fig. 2 and the corresponding optimization formulation is presented previously. The superstructure consists of three stages including segregation, the conversion of MSW, and the resulting products. In the first stage (segregation), it is assumed that the MSW is screened at the MSW source points which allow it to be sorted into different constituents based on their properties. It is expected that the recyclable separation is performed at the source point by the residents and then collected by the local authorities. Different components are sent to different treatment and conversion technologies to be transformed into various products. The list of waste processing technologies including waste to energy technologies, composting, MRF as well as landfill. The corresponding yields are presented in Table 1 . Note that additional processing technologies can be included in the superstructure to enhance the sustainability. Most of the input parameters such as the conversion of waste into products has been taken from the published literature. In the final state, the products obtained from each waste processing technology are presented including electricity, bioethanol, and any recyclable materials. It is noted that the recovered heat is only used for process operation as it is practically not for sale in Thailand. In terms of the cost analysis, the annual capital, operating cost and the selling price of the products have been given in detail in Tables 2 and 3 , respectively.

It is important to note that the transportation and waste collection costs are not included in the economic analysis because this study aims to determine the optimal processing pathway for converting MSW into valuable products. The transportation and waste collection costs are important elements in MSW management from economic viewpoint because they are associated with a large fraction of the total cost so exclusion of these costs can have a great influence on making the ultimate decision by the practitioners or policy makers. However, exclusion of these costs is not significantly different for each scenario in technology specific analysis. It is noted that this assumption should be carefully used as it is a case-specific assumption and varies case by case with other factors including collection schemes. The costs presented in Table 2 are estimated since the actual cost may depend on various factors, e.g. raw materials, government incentives, and skilled labor.

\section{Results and discussion}

\section{Optimal waste processing network}

Scenario-based analysis is performed to address the MSW processing problem with respect to the maximization of the annual profit. It is divided into 2 scenarios: Scenario I and II: Scenario I considers all waste processing technologies used to develop the integrated waste treatment facility and Scenario II considers only the landfill technology. The summary of the optimization results has been given in Table 4. The corresponding optimal waste processing pathway is illustrated in Fig. 3 for Scenarios I. The optimal waste processing pathway for the Scenario I consists of AD for the treatment of the organic fractions of MSW, recyclable materials, e.g. plastic, paper, and glass are sent to the MRF. Residues from the MRF are sent to the landfill for final disposal where the leachate generated is sent to the wastewater treatment facility as presented in Table 4. The annual profit associated with the MSW processing pathway in Scenario I is equal to $\$ 6.90$ million USD. It is positive which means that it is profitable and shows economical feasible for the MSW management system. Although the capital cost and operating cost are high, they are compensated for by the large amount of revenue from the recovery of electricity in the $\mathrm{AD}$ of the 
Table 1 List of the waste processing technology used in the superstructure and the product yields per ton of MSW

\begin{tabular}{|c|c|c|c|c|c|c|c|}
\hline \multirow[t]{2}{*}{ Technology } & \multicolumn{6}{|l|}{ Yield } & \multirow[t]{2}{*}{ References } \\
\hline & Electricity (kWh) & Fertilizer $(t)$ & Paper (t) & Plastic (t) & Glass (t) & Bioethanol (t) & \\
\hline Pyrolysis & 490 & - & - & - & - & - & [22] \\
\hline Gasification $\left.\right|^{a}$ & 1000 & - & - & - & - & - & {$[22]$} \\
\hline Gasification $\|^{\mathrm{b}}$ & - & - & - & - & - & 0.255 & [23] \\
\hline Incineration & 340 & - & - & - & - & - & {$[22]$} \\
\hline$A D$ & 187.5 & 0.27 & - & - & - & - & [22] \\
\hline MRF & - & - & 0.9 & 0.75 & 0.89 & - & [13] \\
\hline Composting & - & 0.3 & - & - & - & - & [13] \\
\hline
\end{tabular}

${ }^{\mathrm{a}}$ Gasification I - gasification with electricity generation, ${ }^{\mathrm{b}}$ Gasification II - gasification with bioethanol generation

organic waste, fertilizers and the recycling of paper, plastics and glass. Further analysis reveals that the annual profit is dominated by the revenue of products from material recovery. There are five products obtained from the integrated waste processing facility: electricity, fertilizers, recycled plastic, recycled paper, and recycled glass accounting for 42.6, 21.5, 9.3, 5.7, and 20.9\%, respectively. The annual capital cost involves three waste processing technologies: AD (80.7\%), MRF (16.6\%), and landfill (2.7\%). The annual operating cost of the Scenario I consists of $\mathrm{AD}(57.3 \%)$, MRF (40.8\%), landfill (1.9\%), and additional cost from the leachate treatment $(<0.1 \%)$. Other potential technologies such as gasification or pyrolysis have not been selected because these technologies have larger capital cost and operating cost which cannot possibly be compensated for by the revenue.

It is worth investigating the comparison between the optimal result and the landfill in the Scenario II which is the current practice in many places. The results show that when all waste is sent to the landfill, the annual profit is equal to \$-16.36 million USD. This is negative, meaning that it is not economically viable compared to Scenario I. The annual profit in Scenario II is dominated by the annual capital cost of the landfill accounting for \$15.11 million USD and \$1.51 million USD for the annual operating cost. It is found that revenue is equal to

Table 2 Details of the annual capital and operating cost factors for each waste processing technology per ton of MSW

\begin{tabular}{llll}
\hline Technology & $\mathbf{C C F}\left(\mathbf{\$} \mathbf{y r}^{\mathbf{- 1}} \mathbf{)}\right.$ & $\mathbf{C P F}\left(\mathbf{\$} \mathbf{y r}^{\mathbf{- 1}} \mathbf{)}\right.$ & References \\
\hline Pyrolysis & 400 & 50 & {$[37]$} \\
Gasification I & 250 & 45 & {$[37]$} \\
Gasification II & 447 & 113 & {$[28]$} \\
Incineration & 400 & 40 & {$[37]$} \\
AD & 50 & 5 & {$[37]$} \\
Landfill & 25 & 2.5 & {$[37]$} \\
MRF & 20 & 3.7 & {$[14]$} \\
Composting & 17 & 17 & {$[38]$} \\
\hline
\end{tabular}

\$0 USD per year or there is no product recovery from the landfill site. Although the capital cost and operating cost of Scenario I are higher than in Scenario II, the revenue from the product recovery in Scenario I is much larger than Scenario II. This can compensate for the higher capital cost and operating cost. It is found that Scenario I provides a promising alternative for MSW management in a manner that is both profitable and economically sustainable. The result is consistent with the previous study showing that complete valorization of MSW through MRF and biorefinery integration for waste recovery was able to not only treat the MSW but also give a profit margin [43].

Additionally, it is interesting to study the benefit of the revenue from the payment for waste treatment and disposal or the gate fee charged to the household unit on the selection of the waste processing pathway. At the present, the local administrative organizations receive the payment for treating MSW with the annual rate of $\$ 15.48$ USD per household in Thailand [44]. It is equivalent to $\$ 11.63$ USD per ton of MSW and this revenue is incorporated into Eq. (2) to maximize the annual profit. It is found that the optimal waste processing facility when considering the payment for waste treatment is similar to Scenario I with the annual profit of $\$ 14.54$ million USD which is $\$ 7.64$ million USD more than Scenario I resulting from the payment charged to households for waste treatment and disposal. This indicates that receiving the payment for waste treatment can

Table 3 Selling price of the recovered products

\begin{tabular}{lll}
\hline Product & Price & References \\
\hline Electricity & $\$ 0.20$ USD kWh $^{-1}$ with incentive & {$[39]$} \\
Fertilizer & $\$ 70 \mathrm{USD} \mathrm{t}^{-1}$ & {$[38]$} \\
Recycled paper & $\$ 66.67 \mathrm{USD} \mathrm{t}^{-1}$ & {$[40]$} \\
Recycled plastic & $\$ 90 \mathrm{USD} \mathrm{t}^{-1}$ & {$[41]$} \\
Recycled glass & $\$ 53 \mathrm{USD} \mathrm{t}^{-1}$ & {$[40]$} \\
Bioethanol & $\$ 971 \mathrm{USD} \mathrm{t}^{-1}$ & {$[42]$} \\
\hline
\end{tabular}


Table 4 Summary of the optimal waste processing facilities in Scenarios I, II and the optimal waste processing facility under uncertainty

\begin{tabular}{|c|c|c|c|c|}
\hline Details & Unit & Scenario I & Scenario II & Optimal under uncertainty \\
\hline Annual profit & $10^{6} \mathrm{USD}_{\mathrm{yr}} \mathrm{r}^{-1}$ & 6.90 & -16.63 & 6.64 \\
\hline CAP & $10^{6}$ USD $_{\mathrm{yr}^{-1}}$ & 24.72 & 15.11 & 24.72 \\
\hline MRF & $\%$ & 16.6 & 0.0 & 16.6 \\
\hline$A D$ & $\%$ & 80.7 & 0.0 & 80.7 \\
\hline Landfill & $\%$ & 2.7 & 100.0 & 2.7 \\
\hline OPE & $10^{6} \mathrm{USD}_{\mathrm{yr}} \mathrm{r}^{-1}$ & 3.48 & 1.51 & 3.48 \\
\hline MRF & $\%$ & 40.8 & 0.0 & 40.8 \\
\hline$A D$ & $\%$ & 57.3 & 0.0 & 57.3 \\
\hline Landfill & $\%$ & 1.9 & 99.3 & 1.9 \\
\hline Wastewater treatment & $\%$ & $<0.1$ & 0.7 & $<0.1$ \\
\hline SALE & $10^{6} \mathrm{USD}_{\mathrm{yr}} \mathrm{r}^{-1}$ & 35.10 & 0.00 & 34.87 \\
\hline Electricity & $\%$ & 42.6 & 0.0 & 42.9 \\
\hline Fertilizer & $\%$ & 21.5 & 0.0 & 21.6 \\
\hline Recycled paper & $\%$ & 9.3 & 0.0 & 9.0 \\
\hline Recycled glass & $\%$ & 5.7 & 0.0 & 21.0 \\
\hline Recycled plastic & $\%$ & 20.9 & 0.0 & 5.5 \\
\hline
\end{tabular}

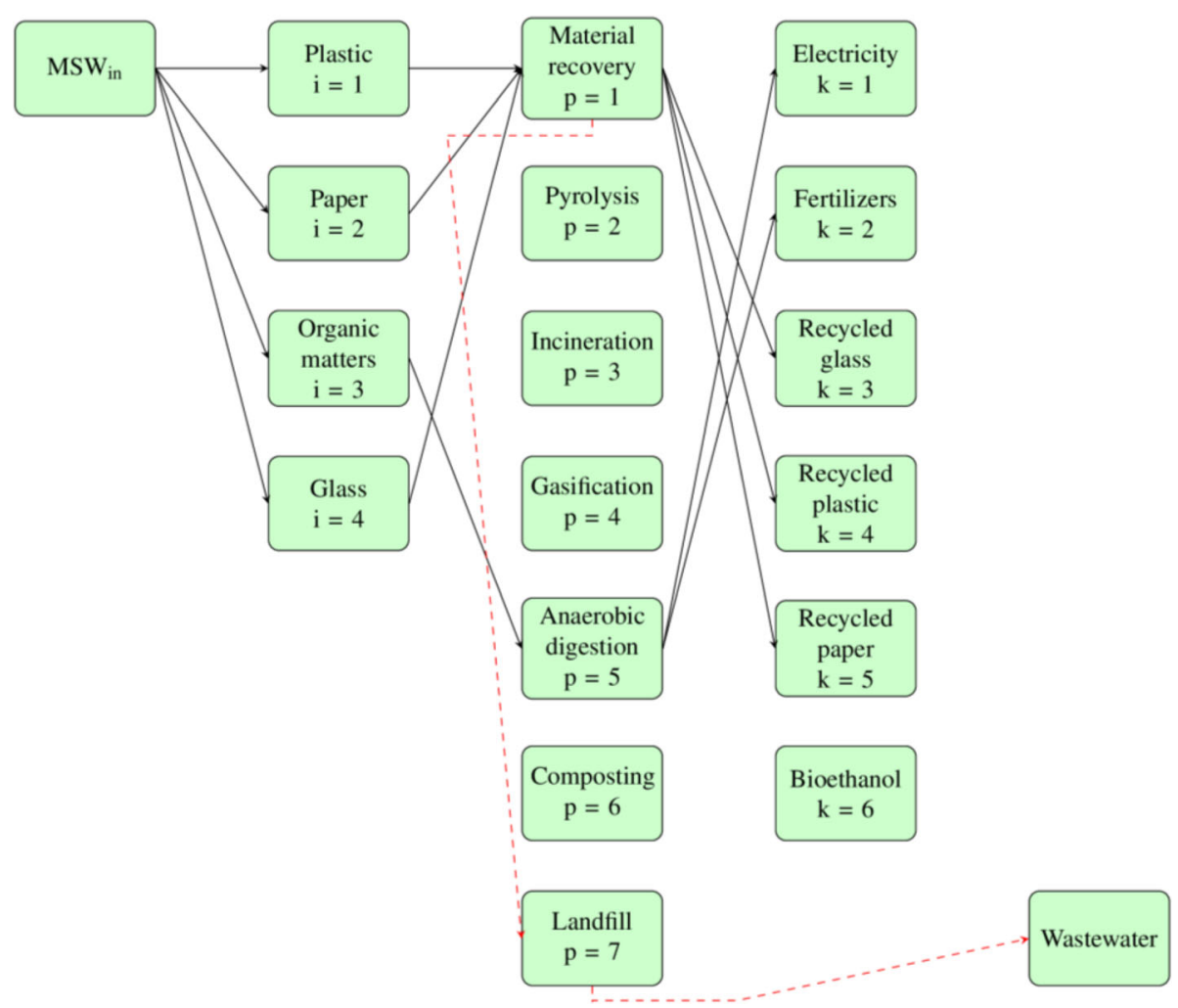

Fig. 3 The optimal waste processing configuration for Scenario I 
increase positive cash flow and the optimal waste treatment facility becomes more profitable. Further analysis reveals that an increase or decrease in the treatment and disposal fee does not affect the optimal waste processing pathway except the value of the annual profit. The results from Scenario I can be a guideline for the decision-makers or local authorities to use to focus on the potential waste processing alternatives for sustainable waste management in Ubon Ratchathani Province.

\section{Uncertainty analysis}

In this study, the yields of the products are considered to be included in the set of uncertainty as defined in Table 5. These parameters represent the performance of each waste processing technology which may be different from plant to plant. A fluctuation in the yield of the products may require the recourse action of changing the waste streams to other waste processing technologies. The uncertain parameters were sampled based on the Latin hypercube sampling technique to define $50 \mathrm{fu}$ ture scenarios with a uniform probability distribution in order to reflect the characterization of uncertainty. It is assumed that there is no correlation between the uncertain parameters. After the 50 future scenarios were generated, a separate optimization problem was solved. The results show that two different waste processing pathways are selected as a function of the uncertainty realization. The majority of the solutions with respect to the uncertainty realization (94\%) select similar waste processing network as in Scenario I as mentioned before. For the second waste processing network (6\%), it consists of composting organic waste instead of AD. Paper, plastic and glass are sent to the MRF for plastic and glass recovery while the remaining materials from the MRF are sent to the landfill. The cumulative probability distribution of the objective function is illustrated in Fig. 4 where the objective function (the annual profit) is displayed on the $\mathrm{x}$-axis and the cumulative distribution

Table 5 Uncertain parameters and domain definition with uniform probability distribution

\begin{tabular}{lllll}
\hline Uncertain parameter & Unit & Mean & Max & Min \\
\hline Electricity yield from incineration & $\mathrm{kWh} \mathrm{t}^{-1}$ & 340 & 408 & 272 \\
Electricity yield from gasification I & $\mathrm{kWh} \mathrm{t}^{-1}$ & 1000 & 1200 & 800 \\
Electricity yield from AD & $\mathrm{kWh} \mathrm{t}^{-1}$ & 187.5 & 225 & 150 \\
Electricity yield from pyrolysis & $\mathrm{kWh} \mathrm{t}^{-1}$ & 490 & 588 & 392 \\
Bioethanol yield from gasification II & $\mathrm{t} \mathrm{t}^{-1}$ & 0.26 & 0.31 & 0.20 \\
Paper yield from MRF & $\mathrm{t} \mathrm{t}^{-1}$ & 0.9 & 1 & 0.72 \\
Plastic yield from MRF & $\mathrm{t} \mathrm{t}^{-1}$ & 0.75 & 0.9 & 0.6 \\
Glass yield from MRF & $\mathrm{t} \mathrm{t}^{-1}$ & 0.89 & 1 & 0.71 \\
Fertilizer yield from AD & $\mathrm{t} \mathrm{t}^{-1}$ & 0.27 & 0.32 & 0.22 \\
Fertilizer yield from composting & $\mathrm{t} \mathrm{t}^{-1}$ & 0.3 & 0.36 & 0.24 \\
\hline
\end{tabular}

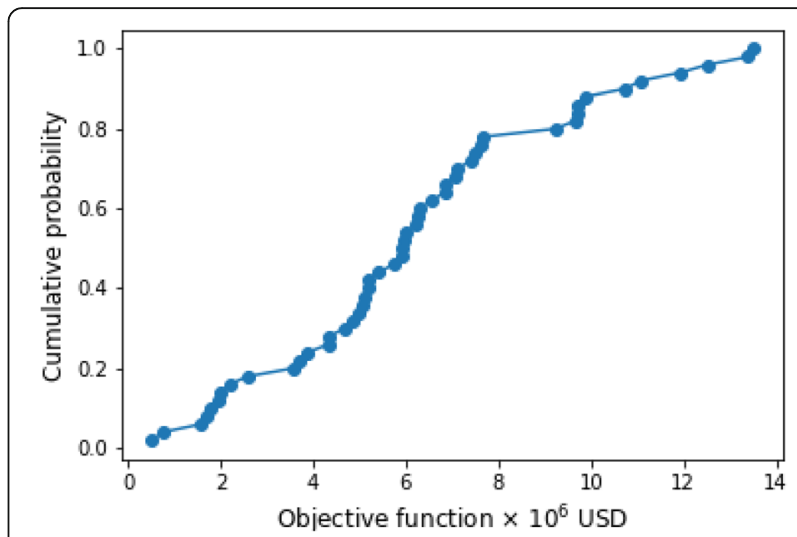

Fig. 4 Cumulative probability distribution of the objective function

on the $y$-axis represents the probability that the objective function will be lower than the stated value. It was found that a variability of the objective function can be observed ranging from $\$ 0.51$ to $\$ 13.48$ million USD per year. To compare this with the optimal solution in Scenario I as presented in Table 4, it can be found that $66 \%$ of the scenarios yields a lower objective function and $6 \%$ yields a different waste processing configuration. This indicates that the uncertainty in terms of the product yields has a large impact on the performance of the pathway and the associated decision-making, so it is important to consider carefully in the decision-making process.

Finally, the optimization problem under uncertainty is formulated and solved as presented in Eq. (13). The MILP problem consists of 16,501 constraints and 4600 binary variables. The summary of the optimal solution under uncertainty realization is presented in Table 4 . The results show that the annual profit obtained is $\$ 6.64$ million USD. The optimal waste processing network under uncertainty has a similar network to the optimal waste processing network without considering uncertainty (Scenario I) with a lower objective function of $3.9 \%$. This indicates the robustness of the optimal solution. This proposed methodology is expected to be a decision-making tool for the local authorities, and/or engineers. It can be used for comparing waste processing technologies and for the selection of the best waste processing technologies among the alternatives with respect to the desired criteria in order to provide the optimal solution while complying with the standard regulations. Note that the current study has presented the underlying theory and practical implementation of the proposed methodology based on an illustrative example. Future studies will consider i) updating and expanding the database on the processing technologies in a superstructure, and ii) evaluating the environmental impact. 


\section{Applicability and limitations}

In this study, a superstructure optimization framework is developed to select the optimal waste processing technology which is a challenging task for the design and retrofit of the waste management system. The proposed framework is particularly suitable for use as a decisionmaking tool, relatively easy to develop and able to guarantee the optimal solution. It can be applied to several systems ranging from villages, cities and countries provided with well-defined boundaries and readily available data such as existing technologies, the annual capital and operating costs. The countries with different waste compositions, technologies, socio-economic conditions can apply such a framework to determine the most suitable waste processing technologies in their regions. The evaluation results can provide valuable implication for best practices in environmental or MSW management for the decision-makers. It should be noted that it is unlikely to conclude the best MSW management from the evaluation results for the whole world because of difference in geographical conditions, socio-economic conditions and technological development. The ultimate decision of implementation depends on the weighted preferences with respect to the decision-makers.

The limitations of the proposed techniques involve superstructure generation. It is important to postulate a set of process alternative illustrated by a superstructure to define an appropriate search space because the process configuration that is not postulated as part of the search space cannot be an optimal solution. Therefore, a systematic approach to generate a comprehensive superstructure is needed. Another limitation of the proposed technique is to select an appropriate degree of approximation. Conversion of waste processing technologies is based on the nominal values. It is possible to incorporate process thermodynamic and transport phenomena to predict process behavior. However, this may give rise to non-convex nonlinear expression which may result in intractability or it is unlike to obtain the optimal solution with the current computational capability [45].

\section{Conclusions}

This paper presents the potential for superstructure optimization in the design of an integrated waste treatment facility. The proposed method is applied for the case study in Ubon Ratchathani Province, Thailand to illustrate its applicability. The results have shown that the proposed waste processing pathway is economically viable in reference to a positive annual profit. This is important because the integrated waste treatment facility has presented the concept of a circular economy which is the driving force towards sustainability. Also, it is suggested that the integration of multiple waste processing technologies to recover valuable resources and reduce waste disposal at landfills is the most suitable strategy for the waste management system rather than using a centralized single technology as in the current practice in some regions. After that, the uncertainty is incorporated into the optimization framework. Variations in the waste processing network and the objective function values in the different scenarios are obtained. The developed approach is expected to support and evaluate the waste processing technologies used in the design and retrofitting of the waste processing facility. Future work will focus on the updating and extension of the superstructure, the evaluation of the environmental impacts of the different waste processing networks as well as the flexibility of the waste processing network as a whole.

\section{Acknowledgements}

The author would like to acknowledge Department of Chemical Engineering, Ubon Ratchathani University for research facility support.

\section{Authors' contributions}

$\mathrm{CP}$ conducted research, developed the mathematical optimization framework, prepared, read and approved the manuscript. SM provided constructive feedbacks and revised the manuscript. The author(s) read and approved the final manuscript.

\section{Funding}

This work was supported by Thailand Research Fund (TRF) under project MSG6080255.

\section{Availability of data and materials}

All data generated or analyzed during this study are available from the corresponding author on reasonable request.

\section{Competing interests}

The authors declare they have no competing interests.

Received: 8 June 2020 Accepted: 7 November 2020

Published online: 18 November 2020

\section{References}

1. Verma RL, Borongan G, Memon M. Municipal solid waste management in Ho Chi Minh City, Viet Nam, current practices and future recommendation. Procedia Environ Sci. 2016;35:127-39.

2. Hoornweg D, Bhada-Tata P. What A Waste: A Global Review of Solid Waste Management. Washington, DC: World Bank; 2012.

3. Dhokhikah $Y$, Trihadiningrum $Y$. Solid waste management in Asian developing countries: challenges and opportunities. J Appl Environ Biol Sci. 2012;2:329-35.

4. PCD. Situation Report on Current Disposal Sites of Municipal Solid Waste in Thailand in 2018. Bangkok: Pollution Control Department; 2019. http://www. pcd.go.th/file/Thailand\%20Pollution\%20Report\%202018_Thai.pdf [in Thai].

5. PCD. Booklet on Thailand State of Pollution 2018. Bangkok: Pollution Control Department; 2019.

6. Dong CQ, Jin BS, Li DJ. Predicting the heating value of MSW with a feed forward neural network. Waste Manage. 2003;23:103-6.

7. Moya D, Aldas C, Lopez G, Kaparaju P. Municipal solid waste as a valuable renewable energy resource: a worldwide opportunity of energy recovery by using Waste-To-Energy Technologies. Enrgy Proced. 2017;134:286-95.

8. Pour N, Webley PA, Cook PJ. Potential for using municipal solid waste as a resource for bioenergy with carbon capture and storage (BECCS). Int J Greenh Gas Con. 2018:68:1-15.

9. Tsui TH, Wong JWC. A critical review: emerging bioeconomy and waste-toenergy technologies for sustainable municipal solid waste management. Waste Dispos Sustain Energy. 2019;1:151-67. 
10. Ikhlayel M, Nguyen LH. Integrated approaches to water resource and solid waste management for sustainable development. Sustain Dev. 2017;25:46781.

11. Zaman AU, Lehmann S. The zero waste index: a performance measurement tool for waste management systems in a 'zero waste city'. J Clean Prod. 2013;50:123-32

12. Guibrunet L, Calvet MS, Broto VC. Flows, system boundaries and the politics of urban metabolism: waste management in Mexico City and Santiago de Chile. Geoforum. 2017;85:353-67.

13. Markic DN, Carapina HS, Bjelic D, Bjelic LS, Ilic P, Pesic ZS, et al. Using material flow analysis for waste management planning. Pol J Environ Stud. 2019;28:255-65.

14. Pressley PN, Levis JW, Damgaard A, Barlaz MA, DeCarolis JF. Analysis of material recovery facilities for use in life-cycle assessment. Waste Manage. 2015;35:307-17.

15. Khandelwal H, Thalla AK, Kumar S, Kumar R. Life cycle assessment of municipal solid waste management options for India. Bioresour Technol. 2019;288:121515.

16. Mencarelli L, Chen Q, Pagot A, Grossmann IE. A review on superstructure optimization approaches in process system engineering. Comput Chem Eng. 2020;136:106808.

17. Umeda T, Hirai A, Ichikawa A. Synthesis of optimal processing system by an integrated approach. Chem Eng Sci. 1972;27:795-804.

18. Khor CS, Chachuat B, Shah N. Fixed-flowrate total water network synthesis under uncertainty with risk management. J Clean Prod. 2014;77:79-93.

19. Puchongkawarin C, Gomez-Mont C, Stuckey DC, Chachuat B. Optimizationbased methodology for the development of wastewater facilities for energy and nutrient recovery. Chemosphere. 2015;140:150-8.

20. Ali RA, Ibrahim NNLN, Lam HL. Conversion technologies: evaluation of economic performance and environmental impact analysis for municipal solid waste in Malaysia. Processes. 2019;7:752.

21. Cimpan C, Maul A, Jansen M, Pretz T, Wenzel H. Central sorting and recovery of MSW recyclable materials: a review of technological state-ofthe-art, cases, practice and implications for materials recycling. J Environ Manage. 2015;156:181-99.

22. Ng WPQ, Lam HL, Varbanov PS, Klemes JJ. Waste-to-Energy (WTE) network synthesis for Municipal Solid Waste (MSW). Energ Convers Manage. 2014;85: 866-74

23. Rizwan M, Saif Y, Almansoori A, Elkamel A. Optimal processing route for the utilization and conversion of municipal solid waste into energy and valuable products. J Clean Prod. 2018;174:857-67.

24. Satchatippavarn S, Martinez-Hernandez EM, Hang MYLP, Leach M, Yang AD. Urban biorefinery for waste processing. Chem Eng Res Des. 2016;107:81-90.

25. Lavee D, Nardiya S. A cost evaluation method for transferring municipalities to solid waste source-separated system. Waste Manage. 2013;33:1064-72.

26. Wilson DC, Rodic L, Scheinberg A, Velis CA, Alabaster G. Comparative analysis of solid waste management in 20 cities. Waste Manage Res. 2012; 30:237-54.

27. Abeliotis K, Karaiskou K, Togia A, Lasaridi K. Decision support systems in solid waste management: a case study at the national and local level in Greece. Global Nest J. 2009;11:117-26

28. Khan MMUH, Jain S, Vaezi M, Kumar A. Development of a decision model for the techno-economic assessment of municipal solid waste utilization pathways. Waste Manage. 2016;48:548-64.

29. Fernandez-Nava Y, del Rio J, Rodriquez-Iglesias J, Castrillon L, Maranon E. Life cycle assessment of different municipal solid waste management options: a case study of Asturias (Spain). J Clean Prod. 2014;81:178-89.

30. Santibanez-Aguilar JE, Martinez-Gomez J, Ponce-Ortega JM, Napoles-Rivera F, Serna-Gonzalez M, Gonzalez-Campos JB, et al. Optimal planning for the reuse of municipal solid waste considering economic, environmental, and safety objectives. AlChE J. 2015;61:1881-99.

31. Niziolek AM, Onel O, Floudas CA. Municipal solid waste to liquid transportation fuels, olefins, and aromatics: process synthesis and deterministic global optimization. Comput Chem Eng. 2017;102:169-87.

32. Morero B, Montagna AF, Campanella EA, Cafaro DC. Optimal process design for integrated municipal waste management with energy recovery in Argentina. Renew Energ. 2020;146:2626-36.

33. Awasthi U, Marmier R, Grossmann IE. Multiperiod optimization model for oilfield production planning: bicriterion optimization and two-stage stochastic programming model. Optim Eng. 2019;20:1227-48.
34. Bozkurt H, Quaglia A, Gernaey KV, Sin G. A mathematical programming framework for early stage design of wastewater treatment plants. Environ Modell Softw. 2015;64:164-76.

35. Nikzad E, Bashiri M, Oliveira F. Two-stage stochastic programming approach for the medical drug inventory routing problem under uncertainty. Comput Ind Eng. 2019;128:358-70.

36. Boonpa S, Sharp A. Waste-to-energy policy in Thailand. Energ Source Part B. 2017;12:434-42.

37. Kumar A, Samadder SR. A review on technological options of waste to energy for effective management of municipal solid waste. Waste Manage. 2017:69:407-22

38. Pandyaswargo AH, Premakumara DGJ. Financial sustainability of modern composting: the economically optimal scale for municipal waste composting plant in developing Asia. Int J Recycl Org Waste Agricult. 2014; $3: 4$

39. EPPO. Policy of Electricity Purchase: Feed in Tariff. Bangkok: Energy Policy and Planning Office; 2015. http://www.eppo.go.th/images/Power/pdf/FThistory/FiT_2558.pdf [in Thai].

40. WGRSP. History Purchase Price of Recycling Materials. Mueang Phitsanulok: Wongpanit Garbage Recycle Separation Plant; 2020. http://www.wongpanit. com/list_history_price.

41. Tan ST, Lee CT, Hashim H, Ho WS, Lim JS. Optimal process network for municipal solid waste management in Iskandar Malaysia. J Clean Prod. 2014; 71:48-58.

42. CEIC. Thailand Reference Price: Ethanol Price. Bangkok: Census and Economic Information Center; 2018.

43. Sadhukhan J, Martinez-Hernandez E. Material flow and sustainability analyses of biorefining of municipal solid waste. Bioresour Technol. 2017; 243:135-46.

44. Challcharoenwattana A, Pharino C. Wishing to finance a recycling program? Willingness-to-pay study for enhancing municipal solid waste recycling in urban settlements in Thailand. Habitat Int. 2016;51:23-30.

45. Chen Q, Grossmann IE. Recent developments and challenges in optimization-based process synthesis. Annu Rev Chem Biomol. 2017;8:24983.

\section{Publisher's Note}

Springer Nature remains neutral with regard to jurisdictional claims in published maps and institutional affiliations.

Ready to submit your research? Choose BMC and benefit from:

- fast, convenient online submission

- thorough peer review by experienced researchers in your field

- rapid publication on acceptance

- support for research data, including large and complex data types

- gold Open Access which fosters wider collaboration and increased citations

- maximum visibility for your research: over $100 \mathrm{M}$ website views per year

At $\mathrm{BMC}$, research is always in progress.

Learn more biomedcentral.com/submission 